\title{
Tillich e Adorno: a cultura como um ponto de intersecção
}

\author{
Daniel Vieira da Silva ${ }^{1}$
}

\section{RESUMO}

A teologia da cultura de Paul Tillich é uma das maiores contribuições deixadas pelo autor na maneira de se fazer teologia ainda hoje. Pois a partir de uma relação entre religião e cultura, sem desconsiderar os atributos de ambas, se complementam em uma interrelação de substância e forma. $\mathrm{O}$ que dentre outras coisas permite dialogar direta e indiretamente com temas e autores não necessariamente ligados à teologia. Por isso, a proposta deste artigo é desenvolver um diálogo entre Tillich e Theodor W. Adorno por meio da importância que o tema da cultura possui para eles. E então perceber os desafios da experiência religiosa em uma sociedade de massas, administrada sob uma razão tecnológica. Além da cultura, vários outros elementos conceituais cruzam os caminhos desses autores, como, por exemplo, o interesse pelo socialismo e por Karl Marx. Além dos infortúnios históricos de uma Alemanha tomada pelo nazismo e o desafio de um exílio nos Estados Unidos, a amizade nem sempre tão presente, mas perdurada e consentida ao longo do tempo.

Palavras chaves: Teologia da Cultura; Cultura; Tillich; Adorno

\section{TILLICH AND ADORNO: CULTURE AS A POINT OF INTERSECTION}

\begin{abstract}
Paul Tillich's theology of culture is one of the author's main contributions for nowadays theology. Without disregarding the attributes of religion and culture, both complement each other in an interrelation of substance and form, dialoguing directly and indirectly with themes and authors not necessarily related to theology. The purpose of this article is to dialogue
\end{abstract}

\footnotetext{
Mestre em Ciência da Religião pelo Programa de Pós-graduação em Ciência da Religião da Universidade Metodista de São Paulo.
} 
Paul Tillich with Theodor W. Adorno regarding the importance that the theme of culture has for them realizing religious experience challenges for a mass society, managed on a technological basis. In addition to culture, other conceptual elements are considered, such as socialism and Karl Marx. In addition to the historical misfortunes of a Nazi-seized Germany and the challenge of exile in the United States, friendship has not always been so present, but endured and consented over time.

Keywords: Theology of culture; Culture; Tillich; Adorno.

\section{Introdução: Frankfurt e as experiências compartilhadas entre Tillich e Adorno}

Uma aproximação entre aspectos do pensamento de Tillich e Adorno pode ser possível por várias vias em comum que ambos autores percorreram. Não é a proposta aqui causar um reducionismo em semelhanças de conceitos ou comparações forçadas com intuito de corroborar com este encontro. $\mathrm{O}$ elemento em comum escolhido foi o da cultura, ou melhor, como o tema foi valorizado. Enquanto a ênfase selecionada em Tillich é a que aponta a cultura principalmente como uma forma, uma expressão da religião, destaca-se em Adorno a função peculiar da mesma de sua mera transformação em produto a ser produzido, consumido e comercializado por uma sociedade de massas sob a égide do capital.

Além do ponto de partida da relação da cultura alguns pontos de convergência acercam esses alemães e suas peculiaridades. A Universidade de Frankfurt foi o primeiro lugar em comum, iniciada com uma relação acadêmica entre aluno e orientador, seguida pelo cargo de assistência. Não demorou para que eles estivessem lado a lado discutindo sobre temas emergentes daquela época. O advento do socialismo e a ascensão do nacionalismo foram temas centrais em seus debates, assim como uma crítica à burguesia por meio das ideias principais desenvolvidas por Karl Marx, o mais distante possível das doutrinações ou passionalidades apropriadas por diversas correntes marxistas. A perseguição política, o exílio e as causas e consequências do nazismo são obviamente suas experiências comuns, no entanto, a amizade, respeito e admiração são marcas mais fortes presentes que contribuem na busca da esperança de uma constante luta por um mundo que não repita a terrível barbárie. 
A aproximação de Tillich com a chamada escola de Frankfurt, consequentemente um achegamento de Adorno, é sugerida por Ênio R. Mueller como "os círculos de Frankfurt" (MUELLER, 2006, p. 78). Além de assumir a cátedra de filosofia por vários anos na Universidade de Frankfurt, Tillich vivenciou uma grande efervescência intelectual concentrada naquele período. Não apenas na área de filosofia e teologia, todavia, na experiência de um ambiente transdisciplinar com reverberações no campo da afinidade e da amizade fora da universidade, com atividades programadas e mediadas pelo mesmo. É em pequenos círculos de discussão que o contato e amizade com os intelectuais frankfurtianos aconteciam (a política aparecia em posição de destaque). Embora valha ressaltar a distinção de grupos oficiais frequentados por eles: diferentes grupos com membros em comum.

No chamado período de Frankfurt, iniciado em 1929, Tillich assumiu a cátedra de filosofia e permaneceu lá por cerca de quatro anos, lugar em que se reunia nesse pequeno círculo de intelectuais notáveis. Também é um momento no qual a interpretação da história por meio de elementos simbólicos aparece em sua obra "A decisão socialista". Em 1933 foi demitido e perseguido pelo regime nazista. Ainda sobre este episódio, é "fato de esta obra ter sido, possivelmente, um dos motivos para a perda da sua cátedra filosófica em Frankfurt" (cf. GROSS, 2004). Apesar disso, não foge apressadamente, na expectativa de que Hitler seria derrotado em breve. "Sentiu-se tentado de entrar para o movimento subversivo da resistência e permanecer em sua terra" (PARRELA, 2004) e finalmente se vê obrigado a ir embora para os Estados Unidos.

O socialismo foi um importante ponto de intersecção entre grupos compostos pelos intelectuais da universidade: "o pensamento da Escola de Frankfurt se funde sobre uma 'teoria crítica da sociedade', que, no seu aspecto político, é alimentada por aspirações socialistas" (MUELLER, 2006, p. 88). Uma autocrítica sobre a ideologia se torna um elemento comum e de afinidade com o pensamento tillichiano. "Nesse sentido, Tillich está próximo da teoria crítica da escola de Frankfurt" (HIGUET, 2017, p. 219). Os círculos de discussão organizado por ele tinham como fundamento "aprofundar a teoria marxista, especialmente a partir dos escritos do jovem Marx" (IBIDEM). Essa parecia a maior 
partilha dos círculos, unidos pela crítica à sociedade burguesa e um socialismo mais pautado em Karl Marx.

O pós-guerra (Primeira Guerra) que devastara a Alemanha exigia uma transformação radical e que certamente não era o capitalismo que iria proporcionar, tampouco, um socialismo ideologicamente imposto sem fundamentos filosófico ou religioso, cujo risco maior era probabilidade de este se tornar apenas uma representação, uma imagem de uma justiça social que nunca poderia se tornar realidade. A relação de Tillich com o movimento socialista religioso, ocorre principalmente por meio do "círculo de Berlim", um dos múltiplos grupos vinculados ao socialismo religioso. Em 1929, ele aderiu ao partido social-democrata por motivos pragmáticos: diante da ameaça do nazismo, era preciso unir todas as forças do socialismo em torno de um grande partido.

A relação entre Tillich e a escola de Frankfurt se estreitara no vínculo com Adorno. Inicialmente como orientando e depois como assistente na universidade, participava dos círculos, lugar em que defendeu seu exame de habilitação orientado por Tillich em 1931 com uma tese ${ }^{2}$ sobre Kierkergaard:

O filósofo existencialista dinamarquês concebia o estágio estético como inferior ao religioso porque marcado pelas preocupações sensuais e materiais. Adorno inverte as conclusões e afirma que a consciência estética, justamente por sua condição ambivalente, é capaz de fornecer um conhecimento mais acurado das contradições irreconciliadas do mundo real (OLIVEIRA; PUCCI; ZUIN, 2012, p. 26).

Também foi nesse contexto que Adorno estreitara a parceria e amizade com Max Horkheimer, perdurada até a sua morte em 1969. Essa relação profissional e de amizade continuou a ocupar um lugar de destaque nos anos posteriores, nos EUA e no retorno à Alemanha, mesmo que a volta do teólogo da cultura tenha sido rápida, já que optou em se estabelecer de forma permanente, a partir de 1948, ao país que o acolheu e onde também recebeu um grande prestígio, residindo então até o final de sua vida. Os círculos de debates de alguma forma sempre estiveram presentes nessa jornada e ocuparam um papel simbólico

2 Publicada em 1933: "Kierkegaard: a construção do estético". Tragicamente no mesmo dia em que Hitler toma posse. 
marcante de uma época e na tradição de um pensamento filosófico e teológico.

\section{Uma Teologia da Cultura para além da obra}

A obra Teologia da Cultura foi publicada no Brasil em 2009 pela Fonte Editorial e traduzida por Jaci Maraschin. O conteúdo é formado por uma compilação de textos produzidos por Tillich entre as décadas de 40 e final dos anos 50, reunidos e publicados pela primeira vez em 1959. Como o próprio título sugere a obra possui como eixo central o conteúdo religioso da cultura em uma interpretação teológica sobre diversos temas que a compõe. Apesar de ser uma obra específica do tema, nela é aplicada o conhecido método de correlação presente no pensamento do autor em praticamente todas as suas fases. Trata-se, de maneira sintética, de respostas teológicas às perguntas existenciais do ser humano, cuja obra referida reúne em sua totalidade um exemplo direto desse método em temas que contemplam diversos temas da cultura e religião.

A obra se divide em três partes principais: a primeira faz considerações introdutórias sobre a teologia da cultura contemplando temas filosóficos. Na segunda, ganham destaque as diversas expressões da cultura em especial a arte e suas formas, como também a posição do símbolo no lugar central da linguagem da expressão da religião. A última parte fecha a obra com abordagens diretas de diferentes exemplos culturais, principalmente na distinção entre o oriente e o ocidente. $\mathrm{O}$ tema principal vai além da relação do cristianismo com a cultura, o seu imbricamento mostra uma ligação que sempre existiu e de difícil ou de impossível separação. Além disso, analisar a cultura pode ser uma boa abordagem para se atualizar os elementos religiosos que a permeiam, atualizando e distinguindo em diferentes momentos e contextos históricos.

Como é característico de toda trajetória do pensamento de Tillich, o lugar entre religião e cultura também é a fronteira. Talvez seja esse o melhor exemplo em que o autor executa essa espécie de princípio metodológico ao se recusar justapor um em detrimento do outro. Esse conceito acompanha traços fundamentais de sua vida e pensamento como, por exemplo, o lugar em que viveu e nasceu, dividida em dois 
continentes e na virada de dois séculos. O seu pensamento também se articulou nesse processo fronteiriço, entre essencialismo e o existencialismo, na sua filosofia, já na teologia, os conceitos de princípio protestante e a substância católica são fundamentais. O que sempre favoreceu uma reflexão aberta e de forma interdisciplinar com outras áreas do saber, inclusive com a cultura em vários momentos presentes como marco dessas fronteiras com a filosofia e teologia, sobretudo na experiência religiosa.

Toda expressão ou ação religiosa é uma expressão enquanto forma da cultura. "A Religião é a substância da cultura; a cultura é a forma da religião" (TILLICH, 2006, p. 53). A necessidade do uso da linguagem para comunicar já é o suficiente para sustentar a segunda parte dessa afirmação. Já a primeira necessita de um uso específico de interpretação sobre religião. Tillich a concebe como um ultimate concern, uma espécie de preocupação existencial latente, uma necessidade de sentido incondicional para a vida. De maneira que haja uma substância religiosa acessada por meio de formas da cultura cujo potencial de produção de sentido está contido. Isso não significa que toda edificação cultural na história da humanidade seja essa fonte de sentido. Pelo contrário, apenas aquilo que toca ou constitui existencialmente o ser humano em sua condição subjetiva em relação à história, na experiência religiosa que está em jogo, aquilo que constrói sentido às funções criativas da vida, aquilo pelo qual vale a pena arriscar a vida porque sem ela não seria possível viver.

A religião possui uma função auto-transcendente da vida, mas ao transcender os conflitos ela se envolve em outros, pelo fato de a religião expressar os dois extremos da dignidade humana, apenas ela pode expressar ao máximo sua grandeza, como também sua profanação que marca uma ambiguidade da religião. Quando se profaniza a religião, ela é transformada em um objeto finito, logo, a manifestação do sagrado na função religiosa é negada, também a experiência da realização, pois não se pode apontar para além dela mesma. Um exemplo dessa redução da religião em apenas uma forma cultural sem substância pode ser compreendida na expressão da cultura como a forma da religião e a moralidade como sua substância. Assim, a religião seria apenas a 
cultura e moralidade, não há nenhum elemento transcendente, resta o produto da criatividade da cultura.

O problema dessa diminuição da religião é que ela é o passo anterior ao seu total descarte e negação como função do espírito, tratando-a apenas como uma ideologia que deve ser superada, negando as suas formas cognitivas e transcendentes. Nessa condição pode ser facilmente uma força manipuladora, especialmente de um controle de massa. Em nosso contexto político temos o exemplo de uma representação significativa e organizada no Congresso nacional, cujo discurso religioso pauta desde diretrizes de ações políticas até a defesa de normatizações de uma visão religiosa e particular em aspectos privados da vida. Infelizmente, quando a substância religiosa é retirada, espaços se abrem para fanatismos, violências, preconceitos e a comercialização da mesma como um produto cultural a ser consumido como um fim em si mesmo. Mas quando a religião é tratada como uma experiência do incondicional é impossível negar e separar os seus aspectos presentes em todas as dimensões da vida.

Mas se a religião como substância da cultura é experimentada na integralidade do sujeito, como ela pode ser vivenciada em uma sociedade de massas em que a particularidade e a razão do sujeito são fragilizadas e instrumentalizadas em prol de uma sociedade totalmente administrada? Para refletir principalmente sobre os aspectos e possibilidades da cultura dessa sociedade é que recorremos às contribuições de Theodor W. Adorno, seja pela sua proximidade com Tillich, como também, por aspectos que torna este frankfurtiano tão próprio.

\section{A religião em uma cultura de massa}

Uma das possíveis definições de religião pode ser encontrada naquilo de mais fundamental, na última instância de nossa preocupação: naquilo que toca nossa existência humana; uma definição também caracterizada pelo fim da separação entre o secular e o sagrado. A superação dessa dicotomia é possível a partir intepretação da religião como "o estado em que somos tomados pela preocupação suprema, não restrito a determinado âmbito" (TILLICH, 2009, p. 82). Logo, todas as dimensões de nossa vida se tornam potencialmente espaço para a expressão do sagrado. O fato de a totalidade de nossas ações não portarem esse 
conteúdo não significa necessariamente uma contradição, apenas demonstra a condição humana de alienação ou de queda, impedindo-a de ser o que ela deveria ser. Quando atestamos essa separação, esbarramos com uma condição de impedimento de ser.

Essa compreensão de religião tillichiana tende a fugir de um conceito rígido, talvez isso não seja possível, todavia, a religião é abarcada em uma relação direta com a fé, como uma "preocupação suprema com aquilo que nos preocupa em última análise" (TILLICH, 2009, p. 81). Ambas possuem um sentido ontológico geral como algo que aponta para o incondicional, embora a fé se localize mais precisamente como a essência da religião. Não se trata de uma concepção subjetiva, porque ela não é apenas um estado emocional ou sentimental, se envolve em elementos do sujeito que se misturam com o todo. Além disso, preocupação última é o que nos toma ou o que deveria nos tomar e culmina em ação. Já a sua redução à imanência humana é recusada porque ela não é "como algo que possa ser reduzido simplesmente a uma produção, uma projeção ou uma configuração humana" (GROSS, 2013). A complexidade entre o transcendente e a ação humana também está imbricada no conceito de fé relacionado à religião.

A fé e a religião são muito próximas e inter-relacionadas na teologia tillichiana. O conceito de religião não é estático, mas forjado por um movimento que se baseia no elemento incondicional que precisa ser descontruído, por conta da sua necessidade de se colocar em formas condicionais para que possamos apreendê-lo. Ao reconstruir os elementos condicionais, a base ainda precisa ser o incondicional, por isso, ao mesmo tempo protesta e supera o próprio conceito. Já a fé "é estar possuído por aquilo que nos toca incondicionalmente", (TILLICH, 2002 , p. 5) se trata de um estado no sentido existencial do ser humano, ou melhor, aquilo que fundamenta a sua existência.

Fé e religião apesar de próximas são também distinguíveis uma da outra, pois:

Enquanto o conceito de religião aponta para um elemento ontológico, a fé se relaciona mais ao elemento antropológico-existencial: é o ser humano diante da sua inescapável dimensão religiosa (BALEEIRO, 2017, p. 35). 
A preocupação última é o estado em que o ser humano se encontra diante da angústia e finitude do vazio que precisa ser preenchido. Embora haja outras ênfases e possibilidades de interpretação de fé como estado em Tillich, a adotada neste texto em relação com a cultura é o estado de fé como experiência, ou seja, é a "a própria fé (como) um tipo de experiência de compreensão e, ao mesmo tempo, representação do mundo humano" (BALEEIRO, 2017, p. 41). O recorte dessa experiência aqui fica por conta da participação do sujeito e da sua tomada de consciência do fenômeno da religião, expressa na linguagem da cultura em que ele está inserido.

Na primeira fase ou nos primeiros textos de Tillich o conceito de cultura é apontado pelo menos de três maneiras, captadas por Eduardo Rodrigues da Cruz como: um "cultivo" ou "pensar culto" (Bildung), um aperfeiçoamento das capacidades do ser humano mais no sentido de treinamento, como uma habilidade a ser desenvolvida; "Geistesleben", vida do espírito, a cultura como fundamento que contém as diversas expressões da vida humana; por fim, um todo complexo, uma interpretação da cultura feita a partir de seu estilo que pela transcendência de suas partes constitui este todo (CRUZ apud HIGUET, 2008). No entanto, prevaleceu o conceito compreendido pelo autor como "um processo de refinamento do comportamento (...) e, principalmente, grandes realizações do espírito humano" (HIGUET, 2008). Se aproxima dos conceitos dominantes das ciências sociais que compartilham de um progresso da cultura que expressa o caráter mais nobre, a produção do espírito humano, de maneira especial na arte e na religião, embora a segunda seja também o que torna possível às outras funções do espírito pois se trata de seu fundamento. A religião e a cultura se complementam e interpenetram entre essência espiritual e forma condicionada. Mas a proposta principal desse artigo é refletir sobre as possibilidades da experiência do sujeito nessa relação no contexto da chamada sociedade industrial ou de capitalismo tardio, pois essa foi a vivência fundamental de mundo dos dois autores retratados.

Tillich aponta três características principais do ser humano na sociedade industrial: a técnica e a falta de profundidade são as primeiras e levam às ações completamente apartadas de Deus. O que demonstra a desconsideração da alienação da condição humana, como se a 
capacidade crítica fosse autossuficiente para a emancipação humana. A terceira se trata do existencialismo como um movimento de protesto e questionamento do ser humano nessa sociedade, o situando em um grande vazio desprovido de sentido (TILLICH, 2006, p. 53-56). Nessa condição alienada, ele se torna apenas parte de uma realidade. Todavia, há aqueles que enfrentam essa angústia na criação cultural como em um protesto pela falta de sentido nessa sociedade.

Nesse contexto, a cultura pode ser analisada, dentre outras maneiras, sob o caráter de movimento e protesto. O movimento é inerente à própria definição de industrial em seu aspecto de progresso cujo aceleramento não se restringiu apenas à produção, tecnologia, informação, mas, em praticamente todas as formas de nos relacionarmos com os outros, inclusive conosco. Na maioria das vezes essas relações são intermediadas com possibilidades tecnológicas que condicionam as suas formas. Um efeito colateral direto é a "perda da dimensão da profundidade no encontro com a realidade" (TILLICH, 2009, p. 84), o virtual ou a realidade projetada afeta a maneira como somos "lançados no mundo", para fazer uso de uma expressão heiddegeriana apropriada para este ponto. Sobre essa perda não se trata de responsabilizar a tecnologia em si, mas de criticar o seu uso e o papel exercido por esta na forma como organizamos nosso mundo, marcado sempre por um movimento e que nem sempre é acompanhado por todos.

Quase tudo pode ser previsto e calculado, para cada necessidade humana uma solução perfeita pode ser produzida, há um apontamento para a autossuficiência de todo o desejo. O problema é que as relações se acomodam na dimensão do finito, pelo menos em seu caráter operativo ou prático, enquanto nossos desejos não possuem limites. Tudo isso está relacionado ao caráter no qual o ser humano é retratado nessa sociedade, infelizmente a custo de sua humanidade. Trata-se da reconfiguração do papel do ser humano nessa sociedade, desenvolvido na grande roda que gira todo o sistema de produção. Esta que não se limita a produtos industrialmente fabricados e comercializados, pois quase toda possibilidade de sentido também pode ser fabricada. Deus, que nos últimos séculos teve sua carga horária de trabalho diminuída aos poucos, graças à secularização e eficiência tecnológica, pode então finalmente descansar. O ser humano parece possuir ferramentas o sufi- 
ciente para administrar o mundo sozinho e resolver os seus problemas. Cabe ao criador, caso ele prefira, se ocupar de questões mais simples a preencher a superficialidade da vida.

Dentro das duas principais características da sociedade industrial, entre a falta de profundidade e o total controle dos processos criativos, somos condenados a viver em um sistema contínuo de produção e consumo esvaziado de qualquer possibilidade de sentido que já não seja inerente a essa lógica. Sendo assim, não seria possível romper o ciclo. No entanto, estamos diante de uma afirmação que não é totalmente verdadeira. Encontramos produções culturais expressivas do espírito humano, mesmo após uma sociedade tecnológica recorrer às soluções do tipo deus ex machina para justificar seus problemas intrínsecos e legitimar suas ações. Esse rompimento fica situado no aspecto do movimento, porque nem mesmo uma sociedade com um vasto aparato técnico de controle está imune à contrariedade e resistência, na dimensão do protesto uma saída razoável se apresenta para o rompimento desse ciclo e Tillich percebeu no movimento do existencialismo essa brecha.

"O existencialismo, em sentido amplo, é o protesto contra o espírito da sociedade industrial a partir dela mesma (TILLICH, 2009, p. 87). A crítica se concentra no questionamento do ser, qual o seu lugar, visto que na relação de consumo e produção não há espaço para o ser humano enquanto ser. A sua individualidade, suas peculiaridades que o tornam único em todo o universo é apenas parte de uma realidade criada com praticamente a mesma equivalência dos outros entes na composição do todo. Mas há pessoas que enfrentam essa falta de sentido e encontram na expressão cultural uma forma para externar a situação humana. "São expressões criativas das tendências destrutivas da cultura contemporânea" (TILLICH, 2009, p. 88). Por isso, o protesto nasce a partir da própria cultura, na possibilidade de fissuras desse sistema no encontro com a sua substância. Ou ainda, esta substância se revela no confronto com o não-ser, com aquilo que a nossa cultura não é, essa é uma forma do existencialismo.

A religião expressa na cultura contemporânea, como não poderia ser diferente, também recebe traços dessa relação. Essa cultura é concebida como vários conjuntos diferentes que compõem um grande sistema coerente, já toda cultura de massa é igual por ser centralizada 
e monopolizada pela indústria. Essas são as principais características demonstradas por Adorno e Horkheimer na experiência cultural do sujeito em uma sociedade administrada, pelo que eles definiram como indústria cultural. Uma das eficiências dessa administração dos produtos culturais "provém de sua identificação com a necessidade produzida, não da simples oposição a ela, mesmo que retratasse uma oposição entre a onipotência e impotência" (ADORNO; HORKHEIMER, 1985, p. 128).

O exemplo fica por conta do lazer, divertimento, o tempo teoricamente ocioso, sob esse domínio ele não é uma oposição do trabalho, entretanto, um prolongamento do mesmo. Ao tentar fugir da mecanização da produção do trabalho o resultado é uma reprodução de movimentos que se equivalem, afinal, a decisão do que fazer não é do sujeito, ela está emaranhada nesse complexo entre necessidade produzida e satisfação, entre desejo e promessa que nunca se cumprem. Lógica permeada não apenas na forma de se consumir "cultura", mas na maneira em que nossas relações são transformadas em produtos a serem consumidos e administrados por uma "indústria".

A falta de profundidade das relações da vida, fruto principalmente causado por um esquematismo usurpador da criação humana, nos encaminha para a segunda característica dessa sociedade apontada por Tillich: "para realizar seu destino, o ser humano precisa estar de posse de processos criativos, análogos aos que eram antigamente atribuídos a Deus" (TILLICH, 2009, p. 85). Mesmo em campos diferentes e com suas peculiaridades, ambos os autores corroboram para uma constatação decorrente de uma perfeita conciliação entre nosso estado de alienação e a realidade. Se somos totalmente responsáveis pelos processos criativos, não há mais relevância falar sobre queda ou pecado, só existe regra de consumo; todas as nossas necessidades podem ser supridas. Nossas faltas não estão relacionadas com uma origem que em algum momento foi transgredida e desviada do curso plenamente ideal da vida, agora são somente espaços a serem preenchidos. Não há espaço para o eterno porque a morte foi superada, ou melhor, ela é completamente ignorada enquanto estamos envolvidos em um processo infinito de produção e consumo.

As tensões nas estruturas de poderes e governos, nas diferenças sociais e econômicas e quem sabe até os conflitos religiosos, se ainda 
não desapareceram completamente é só por uma questão de tempo para isso ocorrer. $\mathrm{Na}$ verdade, não demorou muito para percebermos que a Teologia liberal e o Racionalismo superestimaram o papel da razão nesse processo, quase uma crença plena na emancipação humana. O progresso advindo da tecnologia era a divindade não prevista para superar esses pequenos conflitos e diferenças. A dominação expansiva do capitalismo não só não diminuiu as tensões, como também parece ter se transmutado em forma de cultura, religião e mesmo da razão.

\section{O capital entre a religião e a indústria cultural}

A indústria cultural, termo forjado sob a vivência da sociedade estadunidense por Adorno e Horkheimer, cuja aproximação é a referência principal para refletir as características da cultura tratadas na crítica à sociedade. Este conceito se refere principalmente a atender uma nova demanda de uma sociedade concentrada em centros urbanos ao redor das grandes fábricas, com tempo e potencial financeiro para consumir novos produtos culturais que estavam por surgir. O cinema incorpora em si o símbolo desse período. $O$ investimento e a construção de enormes estúdios em Hollywood possibilitaram a produção e popularização de filmes. O objetivo final do produto vai além do gênero, forma e conteúdo desses filmes, assim como o estilo de vida hollywoodiano das atrizes e atores serviam de parâmetro para se definir um padrão de medida a ser seguido:

Do ponto de vista do então novo capitalismo monopolista, era a propositura de um método de adaptação a um mundo econômico sem brechas, totalmente determinado pelo ritmo da maquinaria de produção e da programação para o consumo supérfluo que, por sua vez, deveria realimentar a produção. Era o que os autores chamaram de 'mundo administrado', no prefácio à segunda edição da Dialética do esclarecimento (DUARTE, 2010, p. 42-43).

O filme converge em diversos aspectos, desde a produção do roteiro até a sua exibição nas salas de cinemas. A principal característica da cultura dessa sociedade que se formara: a cultura como uma eterna promessa de realização de uma experiência que jamais poderia ser concretizada. Uma ideologia que solidificava as bases deste capitalis- 
mo extremamente atuante em todas as dimensões da atividade criativa humana, ou seja, a cultura como possibilidade de expressão do humano se mostra uma grande mentira.

Uma característica da cultura marcada pelo pós-segunda guerra mundial é o imenso vazio deixado. Tal vazio parece não ter sido preenchido mesmo em tempos em que ela passa a ser produzida e consumida por uma sociedade de massa. A velocidade e variedade em que os produtos culturais são fabricados e comercializados somente demonstram a quantidade sem necessariamente atingir a profundidade. "O mistério do sentido que se revela em meio à criticidade cultural é também o mistério da própria vida" (SANTOS, 2005, p. 132). Por isso a teologia da cultura direciona sua crítica a esse esvaziamento de sentido que implica no impedimento das funções criativas ou da própria vida. O paradoxo presente é que quanto mais o indivíduo está envolto na cultura, seja na produção ou consumo, mais distante ele está de alcançar este sentido perdido que foram reduzidos a produtos, contudo, continuam presentes em todas as dimensões da vida.

Para Adorno, se debruçar sobre o tema da cultura não é outra coisa senão elaborar a sua crítica de maneira a se considerar os elementos sociais, econômicos e políticos dentro de cada momento histórico. Nesse caso o recorte de análise delimita um momento crucial do plano de consolidação do capitalismo denominado como tardio ou sociedade industrial. Ele é parte importante não só como um pano de fundo, pois sua força de atuação funciona como uma grande locomotiva veloz e incansável, capaz de construir trilhos em todas as direções do mundo que lhe interesse. Ao mesmo tempo em que leva consigo os elementos a serem utilizados na nova maneira de organizar a vida. Trata-se então de uma alta produção tecnológica a produzir e modificar completamente aquilo que apesar de possuir tantas definições, nos referimos como cultura, pois ela contém em si a totalidade da expressão e do fazer humano.

Uma das principais abordagens a respeito da cultura está na coexistência entre o universal e o particular, entre a base e a superestrutura. Isto é não só um problema em Adorno, mas ocupa uma questão central no marxismo "a saber, a relação a ser estabelecida entre 'cultura' (ou consciência, ou existência) e seu conceito socioeconômico, ou "base" (JAMESON, 2011, p. 69), de maneira que a reflexão e crítica à cultura 
não pode ser feita sem se considerar esses aspectos. São problemas ainda não totalmente resolvidos e que também não podem ser completamente ignorados. Ao se criticar os elementos da cultura em uma sociedade burguesa, corre-se o risco de condená-la assim como a rechaça dos aspectos socioeconômicos. Não se pode separar a cultura totalmente desses elementos que a compõem, porém, a tendência é dispensar tudo no mesmo pacote, como retratado por Adorno, comentado a seguir.

Em seu aforismo por nome de "A criança com a água do banho" (ADORNO, 1991, P.36-37) Adorno faz uma observação relevante para a situação da cultura, inclusive uma concepção enriquecida de esperança. Mas antes ressalta o seu caráter ideológico, ou pior, o risco da própria crítica à mentira em que

a cultura simule uma sociedade digna do homem, que não existe; que ela encobre as condições materiais sobre as quais se ergue tudo o que é humano; e que ela serve com seu consolo e apaziguamento, para manter viva a má determinação econômica da existência" (JAMESON, 2011, p. 36).

Esse caráter mentiroso, encobertador da cultura é fundamental para uma sociedade organizada em torno do capital. Por que os sentidos e sentimentos não estão presentes apenas na materialidade, eles cerceiam e se misturam a tudo tornando impossível separá-los. Com isso, identificamos a 'mentira' material da cultura, também apontamos o espiritual como sua parte e não como sua contraposição.

"Na profundidade da cultura está a religião, portanto, o fundamento do sentido tem que ser religioso, assim como a religião, enquanto profundidade de sentido uma vez manifesta, é cultura" (SANTOS, 2005, p. 126). Parece essa uma razoável explicação que sintetiza a teologia da cultura de Tillich e também conclui esse texto. Situar a teologia da cultura em uma experiência de massa se mostra uma proposta pertinente pelos aspectos citados acima. Não conseguimos separar todos os elementos espirituais e materiais contidos em sua gênese, ambos compõem a forma da religião, sendo o espiritual como substância do material, mas sem separar totalmente as duas coisas. Talvez uma pergunta mais necessária seria a de como identificar a forma da religião em uma convivência de massa? Em uma sociedade onde a identidade do sujeito é quase que totalmente absorvida pelo todo, logo, suas experiências já 
não são necessariamente suas. $O$ problema não se mostra diretamente na cultura, mas nessa relação com o indivíduo, apesar de ser cada vez mais complexo captar a forma de uma cultura que se esvai e se refaz quase que constantemente.

\section{Referência Bibliográfica}

ADORNO T. W.; HORKHEIMER M. Dialética do Esclarecimento. Rio de Janeiro: Jorge Zahar, 1985.

ADORNO, T. W. Minima Moralia. Rio de Janeiro, 1991.

BALEEIRO, C. A. S. A fé como estado de preocupação última: interpretação da noção de risco da fé na obra de Paul Tillich. 2017. 191 folhas. Tese (doutorado em ciências da religião). Escola de comunicação, educação e humanidades. São Bernardo do Campo, São Paulo.

DUARTE, R. Indústria Cultural: uma introdução. Rio de Janeiro: Editora FGV, 2010.

HIGUET, E. As relações entre religião e cultura no pensamento de Paul Tillich. Correlatio, São Bernardo do Campo, v. 7, n. 14, 2008.

A teologia de Paul Tillich: utopia, esperança e socialismo. São Paulo: Fonte Editorial, 2017.

.; MARASCHIN, Jaci. A forma da religião: leituras de Paul Tillich no Brasil. São Bernardo dos Campos: Universidade Metodista de São Paulo, 2006. GROSS, Eduardo. Elementos do pensamento de Schelling na obra de Tillich. Numen - Revista de Estudos e pesquisa de religião, Juiz de Fora, v. 7, n. 2, p. 79-99, 2004.

. O conceito de religião em Paul Tillich e a ciência da religião. Correlatio, São Bernardo do Campo, v. 12, n. 24, 2013.

JAMESON, Frederic. O marxismo tardio. São Paulo: Unesp, 2011.

MUELLER, Ênio R. Contatos e afinidades de Paul Tillich com a Escola de Frankfurt. In: BEIMS, Robert W.; MUELLER, Ênio R. Fronteiras e Interfaces: o pensamento de Paul Tillich em perspectiva interdisciplinar. São Leopoldo: Sinodal, 2005.

OLIVEIRA; Newton R.; PUCCI, Bruno; ZUIN, A. A. Soares. Adorno: o poder educativo do pensamento crítico. 5. ed. Petrópolis: Vozes, 2012.

PARRELA, Frederick J. Vida e Espiritualidade no pensamento de Paul Tillich. Correlatio, São Bernardo do Campo, v. 3, n. 5, p. 94, 2004. 
SANTOS, Joe M. G. A Teologia da Cultura. In: BEIMS, Robert W.; MUELLER, Ênio R. Fronteiras e Interfaces: o pensamento de Paul Tillich em perspectiva interdisciplinar. São Leopoldo: Sinodal, 2005.

TILLICH, Paul. Textos Selecionados. São Paulo: Fonte Editorial, 2006. . Teologia da Cultura. São Paulo: Fonte Editorial, 2009. . Dinâmica da Fé. São Paulo: Sinodal, 2002. 